\title{
A PROPOSAL OF A PROCESS MODEL FOR POSTAL ELECTRONIC SERVICE IMPLEMENTATION
}

Bystrík Nemček $^{1}$, Iveta Kremeňová ${ }^{2}$

\begin{abstract}
This article is dedicated to one of the main business processes-implementation of the postal electronic service. Theoretical point of view is focused on Business Process Management (BPM) describing it as a field in systems engineering that focuses on activity of representing processes of an enterprise, so that the current process may be analyzed or improved. The main aim of the practical point of view was to design a model of postal electronic service implementation. A proposal of model is designed in Business Process Model Notation (BPMN), which is a graphical representation for specifying business processes in a business process model.
\end{abstract}

JEL Classification Numbers: C58, DOI: http://dx.doi.org/10.12955/cbup.v3.604

Keywords: Model, postal, electronic, service, modelling

\section{Introduction}

Information and Communications Technology (ICT) has dramatically changed the area of social and business communications. There is no doubt that ICTs has had an enormous impact on postal operators and operations provided by the Post. There is no reason to think that the impact has been negative; however, the opposite is the case. Today we are facing a tremendous decline of letter-type postal item globally. This is mainly because we live in an information age, and communication is realized mostly electronically. As a reaction to this situation, the question remains: "should Posts innovate and develop new services using application of e-business?” Nowadays, we can see how the postal operators are diversifying and providing new electronic services to their customers in order to satisfy them. Postal electronic services are becoming more prominent all over the world, but there is a difference between developed and developing countries. In the study of Universal Postal Union [UPU] (2012), there are a total of 55 postal electronic services defined.

\section{Classification of postal electronic services}

As stated earlier, the number of postal electronic services is 55 . These services are classified into four groups:

- e-post,

- e-finance,

- e-commerce,

- e-government services (Kremeňová \& Nemček, 2013, 2014).

E-post services involve, for example, public Internet access point in post offices, postal electronic mailbox, direct mail, etc. They are widely developed and strategically important for Posts all over the world. Traditionally, postal services have been used to facilitate communication between citizens and businesses via physical means, such as letters. E-post services are communication services delivered to customers via ICT means. The next one is the area of e-Finance services-services provided by postal operators to their customers using ICTs, e.g. electronic invoicing, online bill payments, or electronic money transfer. E-commerce services include: online shop for philatelic products or SSL web certificates. The last one are e-government services, which are also strategically important. They are run by the government and provided through ICT means, using Posts as a trusted third party. E-government

\footnotetext{
1 Ing. Bystrík Nemček, University of Žilina in Žilina, FPEDaS, Department of Communication, nemcek@fpedas.uniza.sk

2 Ing. Iveta Kremeňová, University of Žilina in Žilina, FPEDaS, Department of Communication, iveta.kremenova@fpedas.uniza.sk
} 
services are, e.g. digital identity, driving license renewal, electronic medical certificates, or online passport application (Nemček, 2012).

\section{Business process management}

The main aim of the Business Process Management (BPM) is to consider the actual situation in the enterprise as a set of activities, which are coordinated and managed in a determined order and to reach all of the enterprise goals defined at each enterprise strategic level.

We can define the business process as a set of coordinated activities executed by each of the enterprise department. These activities are either manual or automated tasks.

The Business Process Management requires at least three levels:

- The analysis and design of business processes in order to reach the strategic objectives,

- The implementation and execution of business processes,

- The stage of business processes control and monitoring and the definition of corrective actions (Tennent \& Friend, 2011).

In Figure 1, these three levels are illustrated as parts of Business Process Management life cycle.

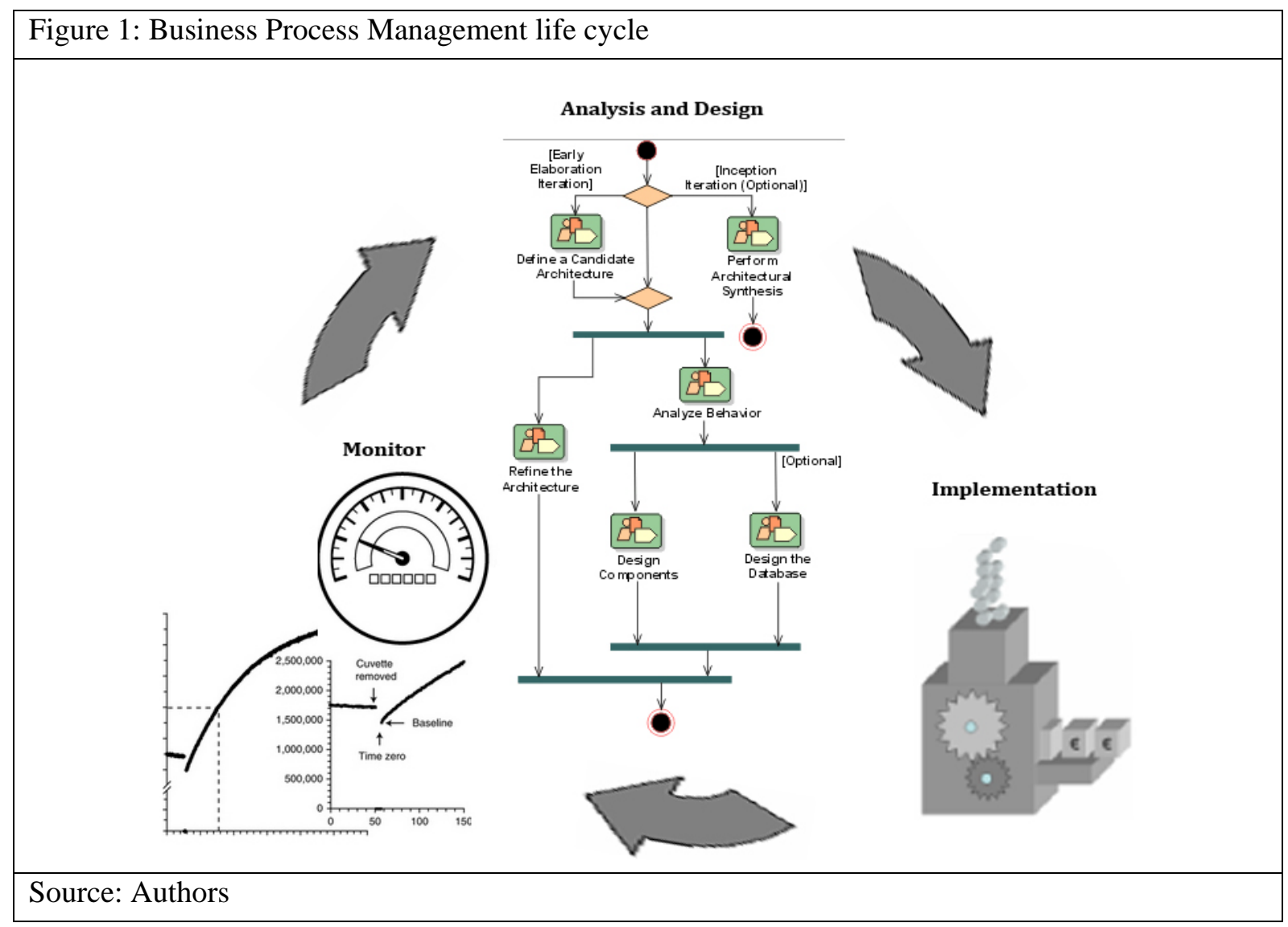

The level of analysis and design of business processes require considerable amount of human interactions and communication. A business analyst is required to have an important area of understanding and reporting their perceptions of the reality of the situation in each organizational unit to the stakeholders involved. There are several format standards on how to report Business Process information. The most practical is the graphical representation, and we can say that is the easiest and the fastest way to maintain, understand, and communicate the information. The main aim of Business Process Modeling is to produce business process models in a business-oriented level of details (Pyle, 2008). 


\section{Business modelling}

The basic definition is that the model is an abstraction of reality. Business Process model consists of the elements, which drive the business, such as the endogenous and exogenous factors acting upon the organizational way of working, and eventually on the enterprise's result.

Process modeling is arguably one of the most important aspects of any organization in terms of the management and control of all of the organizational activities. These activities will range from the highlevel enterprise activities, including mission statements, business processes and requirements, right down to very detailed technical processes that may be executed on a daily basis within the organization (Weske, 2007).

\section{Modelling techniques}

There are many modeling techniques that have been used extensively, and with varying degrees of success, for many years. Many of these techniques are based on visual techniques or, to put it another way, drawing diagrams to represent processes. The list of these techniques includes, but is not limited to:

\section{Flowcharts}

This technique includes classic graphical modeling language that most people have come across at some point in their lives, even if it has nothing to do with software. Although widely used, flowcharts are frequently misused and are poorly understood. One of the biggest problems the flowchart is facing is that they only present a single view of the process model.

\section{RACI matrix tables}

RACI stands for “responsible”, “accountable”, “consulted”, and "informed.” And RACI matrix tables are used to relate process activity within a process that will have a number of stakeholder roles associated with it; and these roles may be responsible, accountable, consulted, or informed. Basic RACI matrix tables are just that - a simple table for cross-referencing between the roles and the activity. However, these tables are often used in conjunction with flowcharts. But, they are often concocted to include some sort of behavior, which makes the tables more complex and add very little value.

\section{BPMN}

Business Process Modeling Notation (BPMN) is the result of the business process modeling initiative, whose aim is to provide a notation that can be readily understood by all business users and that ensures that various business execution languages can be visualized. The three main aims are to define the notation and its association semantics and to amalgamate all best practice modeling notations. Also BPMN provides businesses with the capability of understanding their internal business procedures in a graphical notation and will give organizations the ability to communicate these procedures in a standard manner.

\section{Practical point of view - the proposal of postal electronic service implementation model}

Figure 3 shows the diagram, which illustrates the process of postal electronic service (PES) implementation. It is the maximum or highest level of abstraction. At the start of the process, the need for implementation is identified. This option can come either from the customer, as a demand for some postal electronic services, or it may result from the internal environment of the postal operators. In particular, may be the decision derived from the strategic management of the company based on postal market situation, market trends in postal sector, postal market share, competitors, etc. The next step is the process of analyzing the need to implement postal electronic services. This step considers the need for implementing postal electronic service in all regards. The result of this step may be that the concensus 
of business management, which is responsible for PES. It needs to consider whether result will be positive and the whole process may continue to other step, or negative and the request will be rejected and the process does not continue to the next step (Briol, 2008).
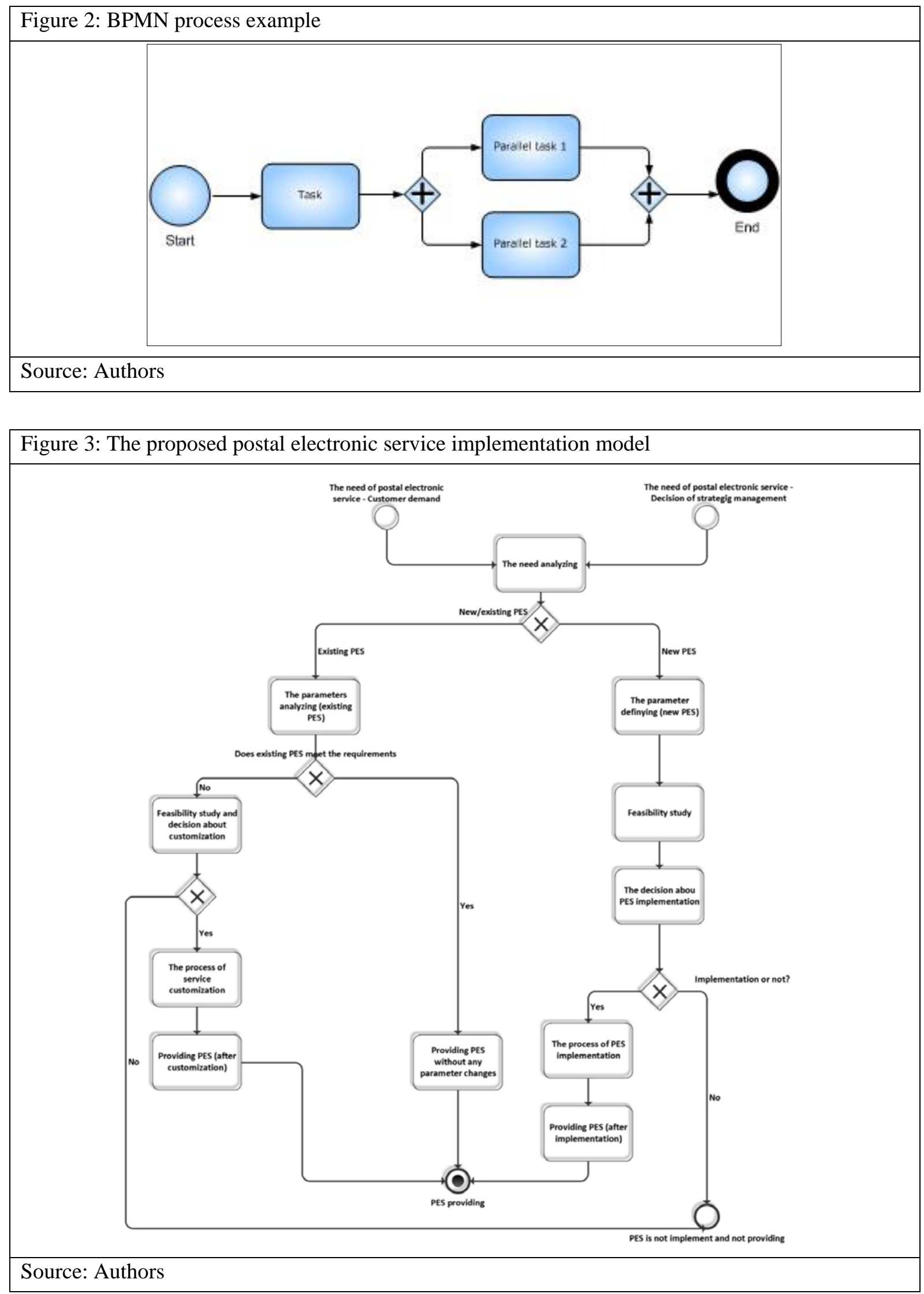
The next step is the decision-making process. In case that the analysis of the postal electronic need is positive, it will continue to the decision-making process, in which the postal enterprise needs to make a decision about implementing the new postal electronic service or customizing an existing postal electronic service. Thus, the entire process is divided into two main branches.

\section{Branch - Existing postal electronic service}

In the first branch, the process begins by analyzing the current parameters for the existing postal electronic service, which will result in the decision-making process. In case the existing postal electronic service fulfills all the requirements of the postal electronic service and the parameters are also satisfactory, then the current postal electronic service is continued without any changes. The process is completed by providing the postal electronic service.

The opposite case in the decision-making process of the postal electronic service requirements happens when the existing postal electronic service does not meet the requirements, which are necessary. In this case, the next step is the feasibility study, and then the decision-making about customization. This means that the next step includes a decision, which has the feasibility study influence upon it. Mainly, the feasibility study determines the way forward in the process. In this case, the feasibility study allows the implementing process to continue to the next step, which is service customization. In the customization process, the postal electronic service parameters will be modified to reach the point in which the postal electronic service meets the necessary requirements. After the postal electronic service customization process is complete, customized postal electronic service will be provided.

Based on the feasibility study, we can also accept a negative opinion relating to service implementation. In this scenario, the existing service cannot be provided and the process ends.

\section{Branch - Existing PES}

The second brand of our model deals with the case where the process continues with the implementation of the new postal electronic service. In this case, the first step is the same as in the previous branch (branch one) - the feasibility study is conducted. Following this step, we decide on further continuation. In case the company decides that the service can be provided, based on the feasibility study, the process of postal electronic service implementation will occur. The next step is providing postal electronic service - as the last step. If the feasibility study points out that the PES cannot be implemented, the final step of the whole process is not to provide or implemente the postal electronic service.

Our model represented high level processes of postal electronic service implementation. It is the high level from an abstract point of view. It can simply be said that our model consists of the steps which are logically organized and interrelated.

\section{Conclusion}

Systematic implementation of electronic postal services allows the postal operator a flexible adaptation in the postal market. The main aim of this concept is to maximize customer satisfaction and provide effective response to the customer needs and market demands. Nowadays, it is very important to adapt to the trends in the area of postal services electronization. In fact, this is the only way forward. Postal operators are increasingly aspiring to develop their electronic business agenda. However, the number of postal e-services currently provided still varies significantly among different countries.

One of the useful areas in business management is business process modeling. As we can see, business process modeling can be used in all of the enterprise activities, as well as in the postal service sector. Thus, this model is highly efficient and is very elaborate. 


\section{Acknowledgement}

This contribution was undertaken, as parts of the research projects: VEGA 1/0748/14 - Research methods of the organisation project aims financing in a competitive environment and KEGA 052ŽU4/2012. On-line learning management in the process of ICT education.

\section{References}

Briol, P. (2008). BPMN—-the Business Process Modeling Notation Pocket Handbook (1st ed.). Bratislava. ISBN 978-1-40920299-8.

Nemček, B. (2012). eCommerce services as a part of postal electronic services. Doprava a spoje. ISSN 1336-7676.

Nemček, B., \& Kremeňová, I., (2013) The level of postal electronic services and PES index analysis in chosen countries. PostPoint. ISBN 978-80-554-0747-0.

Nemček, B., \& Kremeňová, I., (2014). Vplyv inovačnej schopnosti ako ukazovatel’a na PES index vybraných poštových operátorov [Impact of innovative capacity as an indicator of the PES index of selected postal operators]. IPoCC International Postal and e-Communications Conference. ISBN 978-80-86530-94-9.

Pyle, D. (2008) Business Modelling and Data Mining. Morgan Kaufman Publishers. ISBN 978-1-5586-0653-1.

Tennent, J., \& Friend, G. (2011). Guide to Business Modelling (3rd ed.). Canada: John Wiley \& Sons.

ISBN 978-1-118-09553-9.

Universal postal union. (2012), Measuring postal e-service development: a global perspective. Retrieved from, http://www.upu.int

Weske, M. (2007) Business Process Management: Concepts, Languages, Architectures.

Springer. ISBN 978-3540735212. 